\title{
AOR
}

Selected Papers of \#AolR2020:

The $21^{\text {st }}$ Annual Conference of the Association of Internet Researchers

Virtual Event / 27-31 October 2020

\section{RESCRIPTING FAILURE: THE REFLEXIVE STORIES THAT FIELDWORK TELLS}

\author{
Sybille Lammes \\ Leiden University \\ Larissa Hjorth \\ RMIT University \\ Ingrid Richardson \\ RMIT University \\ Kat Jungnickel \\ Goldsmiths, University of London \\ Anna Hickey-Moody \\ RMIT University
}

\section{Brief Introductory Statement}

Researching everyday media practices is a messy and tricky business fraught with uncertainty. In this panel the authors ask how stories of failure, especially during fieldwork, can be rethought as a meaningful emergent method and approach. How can we productively reframe failure as a core part of the research process that cannot be subsumed into the telos of a success story after the research has been completed? How does failure work in research?

Our approach takes a different stance from dominant stories in the tech industry and geek economy, where failure is often represented in linear, heroic, gendered and individualistic ways, retrospectively rendering mess as instrumental to success. Similarly, within academia there are many research processes in which failure is instrumentalised or obscured-from writing up fieldwork into neatly packaged casestudies, to causal accounts of effective intervention. 
Progress narratives of knowledge production have been subject to much debate and criticism. What has been less discussed is how failures work as sometimes uncontainable aspects of research praxes-how they are endemic to the process of data collection and analysis, materializing while in the field. In this panel we suggest that these experiences are core to the thickness of fieldwork-they disclose the messiness and dynamics of the social, and should be included in the stories we tell.

This panel aims to liberate discussion about failure to render it visible and core to understanding the politics and ethics of fieldwork and the research process. Through a series of stories from our fieldwork, we seek to further critical understanding of methodologies and techniques of failure, and argue for our obligations as researchers to talk about what happens when things go wrong. 


\title{
MEDIA SCREENS AND COMPANION ANIMALS: ETHNOGRAPHIC FAILURE IN MORE-THAN-HUMAN CONTEXTS
}

\author{
Larissa Hjorth \\ RMIT University \\ Ingrid Richardson \\ RMIT University
}

Failure is inherent to fieldwork and qualitative methods. It is part of the iterative process. And yet, it is often the case that significant moments of resistance, recalcitrance, and communicative breakdown are rendered invisible or smoothed over in ethnographic analysis. In this paper we discuss our media fieldwork in the domestic context, and how documenting and interpreting the behaviour of companion animals in the home became crucial to understanding digitally mediated kinship and household intimacies. The pets tested our methods and revealed the many inadequacies of human-centric approaches and analytical tools. Here, we consider the challenging and productive role of failure in the ethnographic process, and how listening to the field-especially when it involves more-than-humans-requires us to rethink methodology, research questions and ethics, and explore the meaning of failure beyond human precepts.

When we first entered homes to study mobile games and mobile media practices, we envisaged our project would focus on humans and the various modes of interaction and co-presence networked screens afford. Yet as our research progressed, it became clear that in many homes, humans and their pets are intimately entangled in various forms of digitally mediated kinship. Pets were often the first members we encountered as we approached a participant household. Humans were often quick to introduce them as part of their household - they are household 'members', if not equal to then at least as present, and integral to meaning-making and affectivity, as other household members including children. We thought we were asking questions about human and media dynamics in the domestic sphere, yet animals kept getting in the way. Mobile media and touch screen interfaces became a conduit of playful interaction between humans and their companion animals, affording a unique mode of co-located yet mediated intimacy. We have observed cats playing with iPads, birds strutting back and forth across keyboards and mimicking digital sounds, dogs watching television or participating in video calls, and pets of all kinds intervening in, modifying and disrupting humantechnology relations.

Such encounters left us unable to ignore the significance of human-animal media relations, yet also posed a significant challenge in terms of developing effective modes of data collection and analysis, and appropriate conceptual tools of interpretation. Animal-media relations exposed the limitations - and often the outright failure-of our methodological approach. Animals don't engage with screens like their human counterparts. They get it "wrong". In some homes, pet residents had overt and intentional relationships with media, and in almost all these cases, they used and played with devices "improperly": sitting and sleeping on them, nibbling, scratching, and licking 
them. But in this "wrongness" we can learn much about the excesses and potentialities of haptic media for our embodied being in the world.

The significance of human-animal relations has been the focus of a number of multispecies theorists, including Donna Haraway (2003, 2008), Anne Galloway (2016), Hanna Wirman (2012, 2014), Joanna Zylinska (2014), Rebekah Fox (2006) and others. Their research can be understood as part of the turn away from 'Anthropocene' approaches, problematizing human-centric approaches to ontology, agency, design and ethnographic research. These authors engage new methods that push against anthropocentric interpretive frameworks. For interdisciplinary scholar Wirman (2012, 2014), our definitions of play have been limited by their human-centric focus despite the affordances for much more complex understandings. Wirman's work identifies the need to take account of 'doing haptic play wrongly'. When we open up the field for understanding touchscreen media practices to non-human animals, we must acknowledge that this involves more than 'knowing' hands, as such scenarios of use incorporate a variety of other embodied intentionalities. It can also open up possibilities for interpreting functional devices (such as robotic vacuum cleaners) as playful objects.

The playful practices we observed during our research demonstrate how games not only extend social attachment processes but also offer different platforms for playful agency across human and nonhuman activities. Playfulness often characterizes our interaction with domestic animals, and the haptic dimension of iPads and tablets affords new modalities of cross-species engagement. As interfaces for ambient play, mobile media are unlike television and computer screens, as they involve a synesthetic merging of touch, hearing, and vision. As many of our households revealed, haptic screens have opened up new ways of sharing and playing with our pets. Understanding the multisensorial dimensions of haptic play is pivotal if we are to fully interpret the complexity of haptic interface usage: practices that can be more-than-human and move beyond the eye-hand-screen circuit of sensory perception.

What our fieldwork taught us was the need to redefine digital kinship to include animals. Through the relationality of pets and humans in and around media devices we can better understand how the household is rendered a cartography of affective play. We can consider how kinship as a complex notion involving understandings of care and surveillance is being reworked through digital assemblages. As Rebekah Fox suggests, "Pet-human relationships cross understandings of the human-animal divide through the embodied intimacy of their everyday relations, revealing the importance of animals in everyday human social interactions and conceptions of family, kinship and domesticity." $(2006,532)$. By reframing our research within a multispecies approach, we become better equipped to capture these intimacies and kinship relations in the context of domestic media use.

This paper reflects upon how human and non-human relationality occurs in and around domestic media and the attendant ramifications for how media research is configured and the techniques that are deployed. Through selected scenarios of use, we will explore some of the diverse and emergent modes of haptic play that involve a combination of senses and body parts (human and nonhuman) and challenge our normative expectations of screen use. Tuning in to some of the failures of human- 
centric ethnography, and accounting for animal engagement with haptic screens, quite radically changes how we understand and define play and games as conduits of intimacy and embodied affect.

As homes increasingly become a site for playful media practices across species, and we deploy ethnography or in situ observation as a research method, we find ourselves humbled by the data. Close consideration of actual practices, in all their variation, often works to highlight the gaps and limitations of our assumptions, with humbling effects. Taking a deliberately unassuming approach that deviates from human-centred thinking, pushing against methodological limits, and deliberately exploring ethnographic failure becomes especially important in the age of the Anthropocene. Focusing on humananimal-technology relations, and how they are transforming our ways of being-athome - that most familiar and mundane of places-is one decentring strategy that seeks to productively challenge sedimented ways of seeing and knowing.

\section{References}

Fox, R. (2006). 'Animal Behaviours, Post-human Lives: Everyday Negotiations of the Animal-Human Divide in Pet-Keeping.' Social and Cultural Geography 7, no. 4 (2006): 525-537. https://doi.org/10.1080/14649360600825679.

Galloway, A. (2016). 'More-than-Human Lab: Creative Ethnography after Human Exceptionalism.' In The Routledge Companion to Digital Ethnography, edited by L. Hjorth, H. Horst, A. Galloway \& G. Bell. New York: Routledge, pp. 470-477.

Haraway, D. (2003), The Companion Species Manifesto: Dogs, People and Significant Otherness. Chicago: University of Chicago Press.

Haraway, D. (2008) When Species Meet. Minneapolis: University of Minnesota Press.

Wirman, H. (2012). 'Nonhuman Animal Players: Overcoming Speciesism in Cultural Studies of Digital Game Play.' Paper presented at Crossroads in Cultural Studies, Sorbonne Nouvelle University and UNESCO, July 2-6, 2012.

Wirman, H. (2014). 'Games for/with Strangers-Captive Orangutan (Pongo pygmaeus) Touch Screen Play.' Antennae, no. 30 (Winter 2014): 105-115.

Zylinska, J. (2014). Minimal Ethics for the Anthropocene. London: Open Humanities Press.

\section{INVENTIVE FAILURE: WHAT CAN BE LEARNT FROM RECONSTRUCTING LESSER-KNOWN PATENTS}

Kat Jungnickel

Goldsmiths, University of London. 
Failure is a popular topic of research. It has long been a source of study in fields such as cultural and media studies, sociology and anthropology, science \& technology studies (STS), privacy and surveillance, art, theatre, film and political science. When things go awry, breakdown or rupture they can lead to valuable insights into the mundane mechanisms of social worlds (Latour and Woolgar 1986; Michael 2006; Star 1999; Hawkins 2006). For instance, Susan Leigh Star (1999) has argued that essential infrastructures, such as for water or electricity, are often overlooked and underappreciated until something goes wrong; breakdown reveals behind-the-scenes activities ordinarily taken for granted.

Yet, while failure is a familiar topic of research, failure in and as a tactic of research is far less valued. Research failure - in the form of mess, mistakes and mishaps rarely feature in finished scholarly work. More often, failure is erased from the final polished argument. As Christine Hine writes: "Our methodological instincts are to clean up complexity and tell straightforward linear stories, and thus we tend to exclude descriptions that are faithful to experiences of mess, ambivalence, elusiveness and multiplicity" $(2007,12)$

In this paper I discuss a study that combines both - it explores (and questions) failure as a topic and uses methods that embrace ambiguity and invites the unknown into analysis. The project is an ERC funded project "Politics of Patents (POP): Re-imagining citizenship via clothing/wearable tech inventions 1820-2020". Clothing is a fascinating barometer of socio-cultural and political change. From swimsuits to spacesuits, clothing directly connects social life to the political world - as such is central to changing ideas around the politics of gender and identity, mobility, power relations, inclusion and exclusion. POP is interested in understanding how inventors create new forms of clothing that might be seen to resist, subvert or disrupt social and political norms and beliefs, and in the process, bring new expressions of citizenship into being.

Central to our approach is the idea that clothing is a means through which citizens, and changing ideas around citizenship, are made observable and material through time. We ask: How are different bodies clothed in different discourses over time? What can clothing inventions reveal about hegemonic norms and beliefs? What kinds of citizens do clothing inventions make? Might it be possible to summon into the present lesserknown and non-normative accounts of inventiveness from the past?

Failure features throughout this project. First, we are interested in patents for inventions that few know about. While they were successfully patented, they were potentially never made and perhaps never left the archive/registry. These are often considered failures. Yet, while they may not have radically changed dominant hegemonic narratives of the period, they nevertheless put forward alternative narratives around citizen rights and responsibilities, belonging, inclusion and exclusion. We are curious about the ways these inventors and inventions might be seen as 'providing alternatives, possible sources for the development of new kinds of practices, narratives about belonging to and participating in society' (Holston 1995, 48).

Second, POP approaches the study of invention using inventive methods. Because patents are an experiment in embodied problem solving, we analyse patent text and images and ialso re-make artefacts by closely following the step-by-step instructions provided by inventors in their patents. This process of 'making things to make sense of 
things' (Jungnickel 2018) involves paying close attention, using ethnographic methods, to researching, sewing and wearing artefacts. What we discover in the process of reconstructing garments is a multiplicity of possibilities. There is no way of knowing exactly what the inventor intended, even equipped with their detailed instructions. We make mistakes and take tangents and use more than one version to think with and about the differences between them, and the choices potentially made by the inventor. Also, taking these artefacts (back) out "in the wild", in talks and interactive workshops and by inviting people literally into the research further thickens ethnographic data (Callon and Rabeharisoa 2003).

This approach builds on a long history of reproduction/replication methods in the history of science and STS. Some researchers have cooked from the archives (Nicosia and Connell 2014) while others have reconstructed iconic historic electrochemistry/magnetic experiments (Cavicchi 2008; Eggen et al 2012). While diverse, this work shares common interest in exploring theoretical and tacit knowledge in and through practice. They recognize that not all data can be written or visualised; research is also messy, embodied and sensory. These methods recognize mistakes, tangents and failure as important parts of the knowledge production.

Following the work of gender/queer researchers, we attempt to think with and through failure in patent research as a way of seeking out and embracing alternatives; a way of seeing interruptions, noise and things that don't seem to work or fit that challenge normative and linear conventions. Halberstam's theory of "queer failure' helps in this task. It offers ways to 'think about ways of being and knowing that stand outside of conventional understandings of success" $(2011,2)$. In a similar way, Kornstein (2019) approaches tech failure through bodies and practices that fail to fit conventional categories, and argues that this approach "disrupts binaries not only of masculinity/femininity, but also of disclosure/ concealment, transformation/ stability, and truth/fiction" $(2019,681)$.

Overall, this paper explores how POP approaches failure in multiple ways and attempts to unsettle assumptions built into ideas around citizenship, embodied normativity and digital archives/classification systems. By reclaiming failure, in multiple forms, the project seeks to "escape the punishing norms that discipline behaviour and manage human development" and complicate the "clean boundaries between... winners and losers" (Halberstam 2011, 3).

\section{References}

Callon M. and R. Vololona (2003). Research "in the world" and the shaping of new social identities. Technology in Society 25: 193-204.

Cavicchi, E. (2008). 'Historical Experiments in Students' Hands: Unfragmenting Science through Action and History'. Science \& Education 17: 717-49.

Eggen, P., L. Kvittingen, A. Lykknes, and R. Wittje (2012). 'Reconstructing Iconic Experiments in Electrochemistry: Experiences from a History of Science Course'. Science \& Education 21 (2): 179-89. 
Halberstam, J. (2011). The Queer Art of Failure. Duke University Press.

Hawkins, G. (2006). The Ethics of Waste: How We Relate to Rubbish. Rowman \& Littlefield.

Holston, J. (1995). 'Spaces of Insurgent Citizenship'. Planning Theory 13: 35-51.

Jungnickel, K. (2018). 'Making Things to Make Sense of Things: DIY as Practice and Research'. In The Routledge Companion to Media Studies and Digital Humanities, edited by J. Sayers, 491-502. London and New York: Routledge.

Kornstein, H. (2019). 'Under Her Eye: Digital Drag as Obfuscation and Countersurveillance'. Surveillance \& Society 17 (5): 681-698.

Latour, B., and S. Woolgar (1986). Laboratory Life. Princeton University Press.

Michael, M. (2006). Technoscience and Everyday Life, The Complex Simplicities of the Mundane. London: Open University Press.

Nicosia, M., and A. Connell (2020). 'Cooking in the Archives'. https://rarecooking.com/.

Star, S.L. (1999). 'The Ethnography of Infrastructure'. American Behavioral Scientist43 (3): 377-91.

\section{FRAUD WITH FAILURE: PLAYFUL METHODS IN THE FIELD}

Sybille Lammes

Leiden University

In this paper the intricate relation between play and failure in the field will be discussed, with a specific focus on digital technologies and collaborations that were part of two cases studies: a playful walking experiment in Oxford, and the development of the mobile app Playfields. Both case-studies were collaboratively developed as to experiment with playful methods in the field. They failed in ways that were sometimes scripted and sometimes unintended and could lead to pause, reflection and new approaches. In this paper I will analyse the levels of failure that occurred and to what extent these could be viewed as productive epistemological and ontological instances. This will contribute to how we can understand the reciprocal relation between play and failure in fieldwork, especially when it involves the use of digital technologies, such as mobile phones, GPS tracking devices and digital cameras in a collaborative setting.

As a specification and follow-up of what has been called innovative methods (Lury and Wakeford 2012) this paper wants to further develop the notion of playful methods as an approach to and during fieldwork. This refers to fieldwork in which playful approaches are used that give space to ambiguity in research, thus also opening the door to risky, tricky, unscripted and misunderstood situations. Such glitches and trip-ups can lead to a deeper insight in underlying concepts and assumptions. Furthermore, as with all methods, playful methods go further than describing social realities (Law 2004), but also 
produce them in unexpected, creative and imaginary ways. Playful approaches allow us to step out of a direct functionality or a wish of a direct or specific outcome. This is close to what Donna Haraway recently says about play: "(i)t's not a matter of direct functionality. We need to develop practices for thinking about those forms of activity that are not caught by functionality, those which propose the possible-but-not-yet, or that which is not-yet but still open" (Weigel 2019).

So, this paper takes the assertion of play scholar Sutton-smith a step further that "all forms of play are transformations of one or other of four basic modes by which we know the world": copying, analysing, foreseeing, and synthesing (B. Sutton-Smith 1970). It adds to that play can also create worlds (Sicart 2018) and that failure allows us to identify how the world can and cannot be thought differently. Similar to what Kücklich has claimed about unorthodox play, it "enables us to identify blind spots in our research perspectives and thus discover new avenues of inquiry (...) and can help us recognize flaws in our theoretical models, which are so often built upon the experience of playing by the rules, rather than breaking them"(Kücklich 2007, 357).

That playful methods in particular have the potential to invite failure in the field, has to do to with their resonance as (non)practices. Indeed, as game scholar Jesper Juul pointed out in The Art of Failure: An Essay on the Pain of Playing Video Games (2013) it would be wrong to simply understand playing games in terms of fun, as play is far more related to experiences of pain, frustration and failing to resolve this pain. In this paper I will push this claim a bit further, by proposing that this is not only an important part of games, but also of play in the field and the methods employed in situ.

In this presentation I will concentrate on two playful fieldwork experiences that were fraud with failure. One was a playful exercise, The Time Machine in which we invited peers to traverse Oxford in the role of certain academics, resulting in different trajectories and stories. This project was a failure on many levels, amongst which a paper, Footage, that we wrote and that never got published, also because of a failure in collaboration and interdisciplinarity. The second is a mobile app we as the Playful Mapping Collective developed called Playfields that took failure to the heart in how it asked students to engage with fieldwork. Both the app as well as the collective are now lying dormant, as happens to so many devices, app, games that we as academics develop together for impact and research. This is one level of failure that I would like to discuss further. Other ways of failing that emerged from these cases that I will analyse are: failure of technologies, cheating, tinkering and not taking play seriously.

The overarching questions that lies underneath this paper are: How do contemporary playful methods allow for and encourage failure? How can we conceptualise the relation between methods, play and failure? Can this give an impetus to a different approach to playful methods, that goes further than the game mechanics of winning or loosing as for example used in gamification? By engaging with these questions this paper wants to make a case for including failure and play as possible parts of methods. This can be informative for (collaborative) fieldwork, but also for other research, ranging from Al (e.g. creative indicators in machine learning), data sprints and the use of (digital) research tools. It allows to open up spaces for ludo-epistomologies (Glas and Lammes 
2019; cf. 'anarcho-epistomologies', Feyerabend 1993) which can enable us to do, (for)see, produce and analyse social realities differently.

\section{References}

Feyerabend, P. (1993). Against Method. Verso Books.

Geertz, C. (1972). 'Deep Play: Notes on the Balinese Cockfight'. Daedalus 101 (1): 137.

Glas, R, and S. Lammes (2019). 'Ludo-Epistemology: Playing with the Rules in Citizen Science Games'. In The Playful Citizen: Knowledge, Creativity, Power, 217-34.

Amsterdam: AUP.

Juul, J. (2013). The Art of Failure: An Essay on the Pain of Playing Video Games. MIT Press.

Kücklich, J. (2007). 'Homo Deludens: Cheating as a Methodological Tool in Digital Games Research'. Convergence 13 (4): 355-67.

Law, J. (2004). After Method: Mess in Social Science Research. London: Routledge.

Lury, C., and N. Wakeford (2012). Inventive Methods: The Happening of the Social. Routledge.

Sicart, M. (2018). 'Quixotean Play in the Age of Computation'. American Journal of Play $10(3)$

Sutton-Smith, B (1970). 'The Playful Modes of Knowing.' (unpublished)

Sutton-Smith, B. (2001). The Ambiguity of Play. Cambridge. Mass.: Harvard University Press.

Weigel, M. (2019). 'Feminist Cyborg Scholar Donna Haraway: "The Disorder of Our Era Isn't Necessary"'. The Guardian 20.

\section{DIGITAL AGENCY AND THE AUTHORSHIP OF FAILURE}

Anna Hickey-Moody

RMIT University

Digital platforms and devices fail us consistently. In so doing, they demonstrate agency in ways that even their developers do not understand. My fieldwork data collection relies on digital storage, and uses particular digital applications. Both these processes are marked out by glitches for which there is no immediate answer. These inconsistencies are a digital agency which is impacted further by design problems with apps I use for data collection. - Some apps can only be licensed to an ID for a limited number of times, 
and Apple refuses to make similar IDs. Using my own ID for extra iPads in a moment of desperation, I once created a data monster of new research animations and photos of a family visit, aspects of fieldwork data meshed in with my life data. I spent days trying to untangle this collection of images. These are only some of the ways digital platforms and devices come to shape how we research while we research with them.

Building on my recent work on experiences of failure the gendered research assemblage (Hickey-Moody 2019), I argue that thinking critically about digital agency matters in supporting the work of emerging feminist digital ethnographers, who likely have similar experiences of feeling a failure, experiences that are not yet discussed in the existing literature on digital methods. I argue that digital agency is gendered and is part of the algorithmic worlds in which feminist digital researchers work. As such, we need to develop our own archives of the roles played by digital agency in the production of experiences of failure in research assemblages.

\section{References}

Hickey-Moody, A. (2019). 'Ways of Knowing Failure' MAl: Feminism and Visual Culture: https://maifeminism.com/three-ways-of-knowing-failure/ 